\title{
SELF-TALK AND FEMALE YOUTH SOCCER PERFORMANCE
}

\author{
Janelle J. M. Johnson
}

A Thesis Submitted to the Faculty of Graduate Studies in Partial Fulfillment of the Requirements for the Degree of Master of Science

\author{
University of Manitoba
}

Faculty of Physical Education and Recreation Studies August, 2001

CC Copyright by Janelle J. M. Johnson 2001 
National Library

of Canada

Acquisitions and Bibliographic Services

395 Wellington Street Ottawa ON K1A ON4

Canada
Bibliothèque nationale

du Canada

Acquisitions et services bibliographiques

395, rue Wellington

Ottawa ON K1A ON4

Canada

Your tile Votre reférence

Our file Notre rélárence

The author has granted a nonexclusive licence allowing the National Library of Canada to reproduce, loan, distribute or sell copies of this thesis in microform, paper or electronic formats.
The author retains ownership of the copyright in this thesis. Neither the thesis nor substantial extracts from it may be printed or otherwise reproduced without the author's permission.
L'auteur a accordé une licence non exclusive permettant à la Bibliothèque nationale du Canada de reproduire, prêter, distribuer ou vendre des copies de cette thèse sous la forme de microfiche/film, de reproduction sur papier ou sur format électronique.

L'auteur conserve la propriété du droit d'auteur qui protège cette thèse. $\mathrm{Ni}$ la thèse ni des extraits substantiels de celle-ci ne doivent être imprimés ou autrement reproduits sans son autorisation. 


\section{THE UNIVERSITY OF MANITOBA}

\section{FACULTY OF GRADUATE STUDIES \\ $* * * * *$}

\section{COPYRIGHT PERMISSION PAGE}

Self-Talk and Female Youth Soccer Performance

BY

Janelle J. M. Johnson

A Thesis/Practicum submitted to the Faculty of Graduate Studies of The University of Manitoba in partial fulfillment of the requirements of the degree

of

MASTER OF SCIENCE

JANELLE J. M. JOHNSON @2001

Permission has been granted to the Library of The University of Manitoba to lend or sell copies of this thesis/practicum, to the National Library of Canada to microfilm this thesis and to Iend or sell copies of the film, and to University Microfilm Inc. to publish an abstract of this thesis/practicum.

The author reserves other publication rights, and neither this thesis/practicum nor extensive extracts from it may be printed or otherwise reproduced without the author's written permission. 


\section{Abstract \\ Self-talk and Female Youth Soccer Performance \\ Janelle J. M. Johnson}

This study examined the implementation of a self-talk strategy designed to improve low-drive shot performance. Participants were four female under fourteen provincial soccer players. A two-word self-talk strategy was developed, administered, and evaluated using a single-subject multiple-baseline across-individuals design. Results demonstrated that the self-talk strategy was effective in improving the low-drive shooting performance of the athletes in practice. Qualitative data collected via surveys and interviews revealed the athletes felt increased confidence and ability to focus on relevant cues when shooting. Furthermore, both the coach and the athletes were very satisfied with the results and believed the self-talk strategy to be a significant component in improving low-drive shooting performance. 
Table of Contents

Abstract $\quad$ i

Table of Contents $\quad$ ii

List of Tables $\quad$ v

List of Figures vi

$\begin{array}{ll}\text { Introduction and literature review } & 1\end{array}$

$\begin{array}{ll}\text { Self-talk } & 3\end{array}$

A Behavioral Analysis $\quad 3$

Research on Self-Talk $\quad 4$

Summary of the Research $\quad 12$

Statement of the Problem 13

$\begin{array}{ll}\text { Method } & 15\end{array}$

$\begin{array}{ll}\text { Participants } & 15\end{array}$

$\begin{array}{ll}\text { Experimental Design } & 16\end{array}$

$\begin{array}{ll}\text { Dependent Variable } & 17\end{array}$

$\begin{array}{ll}\text { Assessment Drill } & 18\end{array}$

Treatment Variable: Self-talk Strategy 20

$\begin{array}{ll}\text { Setting and Apparatus } & 21\end{array}$

$\begin{array}{ll}\text { Personnel } & 23\end{array}$

$\begin{array}{ll}\text { Procedural Reliability } & 23\end{array}$

$\begin{array}{ll}\text { Procedure } & 24\end{array}$

$\begin{array}{ll}\text { Baseline } & 24\end{array}$ 
$\begin{array}{ll}\text { Intervention } & 25\end{array}$

$\begin{array}{ll}\text { Follow-up } & 25\end{array}$

$\begin{array}{ll}\text { Treatment of Data } & 26\end{array}$

$\begin{array}{lr}\text { Results } & 28\end{array}$

$\begin{array}{ll}\text { Reliability } & 28\end{array}$

$\begin{array}{ll}\text { Intervention Effects } & 28\end{array}$

Game Performance $\quad 32$

$\begin{array}{ll}\text { Surveys } & 33\end{array}$

Social Validation by Participants 33

Social Validation by Coach $\quad 36$

$\begin{array}{ll}\text { Discussion } & 37\end{array}$

$\begin{array}{ll}\text { References } & 45\end{array}$

$\begin{array}{lr}\text { Appendixes } & 49\end{array}$

Appendix A: Illustration of the low-drive kick 51

Appendix B: Informed Consent for Participants 52

Appendix C: Informed Consent for Parents/Guardians 54

Appendix D: Interview Schedule: Introduction to Self-talk 56

Appendix E: Recording Sheet-Practices $\quad 58$

Appendix F: Recording Sheet -Games $\quad 59$

Appendix G: Low-drive Performance Survey 60

Appendix H: Recording Protocol -Practice Sessions 61

Appendix I: Recording Protocol - Games 62

Appendix J: Interview Schedule-Conclusions regarding Self-talk 63 
Appendix K: Social Validation for Coach 
List of Tables

Table 1: $\quad$ Mean of Low-Drive Shooting Scores

During Baseline and Intervention Phases

31

Table 2: Shooting Assessment in Competition 


\section{List of Figures}

Figure 1: $\quad$ Layout of the Low-Drive Drill 19

Figure 2: Low-Drive Performance in Practice Sessions 30

Figure 3: $\quad$ Pre-and Post Intervention Perceptions of LD Shooting Ability 34 
Self-talk and female youth soccer performance

The human mind is continuously producing ideas that consume the thought processes. These internal cognitions constitute a method of self-communication without actually speaking. Bunker, Williams, \& Zinsser (1993) propose that most of the time we are unaware of this internal dialogue and even more so of its content. Although we may not be conscious of these thoughts they directly affect our feelings which in turn influences our actions (Williams \& Leffingwell, 1996).

Cognitive behavior modification theory holds it's underlying principles within the continuity between an individual's thoughts and his or her overt behavior (Silva \& Weinberg, 1984). The influence of patterns of thought regarding athletic performance can not be overlooked when considering success and failure in sports competition (Finn, 1985). The old belief that thinking disrupts performance is incongruous as we are ceaselessly thinking. It is not thinking in general that equates to an inferior performance, rather it is the intrusion of inappropriate or misguided thoughts that can lead to a deterioration in athletic performance.

Thinking can be destructive to performance when it is negative, as it is theorized to create roadblocks toward achievement goals. Whereas positive thinking can be viewed as an asset to performance when it enhances self-worth and eliminates self-defeating beliefs. Learning to harness our thoughts and cognitions is believed to be of paramount importance in delivering optimal performance in the athletic arena.

With the knowledge that athletic success is not only related to physical performance, but likewise to mental performance, it would be advantageous for athletes to gain control over the mental aspect of competition by monitoring thought 
processes (Williams \& Krane, 1993). Halliwell (1990) proposes the analogy of using the brain like a computer. Athletes can program their brain with positive or negative words and pictures. By thinking or saying negative things the athlete is programming his or her brain for failure, but by thinking or saying positive things the athlete can program for success.

How athletes talk to themselves in practice and competitive situations proves to be quite important. An athlete's self-generated instructional commentary influences performance positively or negatively (Bunker et al., 1993). When thinking is properly structured an athlete can enhance performance and maximize success (e.g., Finn, 1985; Weinberg, Grove, \& Jackson, 1992). Self-talk has been found to have a positive effect on performance with a variety of sports; tennis (Defrancesco \& Burke, 1999; Landin \& Hebert, 1999; McPherson, 2000; Van Raalte, Brewer, Rivera, \& Petitpas, 1994; Weinberg et al., 1992; Weinberg \& Jackson, 1990), figure skating (Ming \& Martin, 1996; Palmer, 1992), basketball (Kendall, Hrycaiko, Martin, \& Kendall, 1990), golf (Kirschenbaum, Owens, O’Connor, 1998; Thomas \& Fogarty, 1997), hockey (Halliwell, 1990), diving ( Highlen \& Bennet, 1983), wrestling (Highlen \& Bennet, 1983), and endurance running (Patrick \& Hrycaiko, 1998; Weinberg, Smith, Jackson, \& Gould, 1984).

The examination of team sports and the implementation of self-talk has lagged behind the research with individual sports. Martin (1997) explains that "sports like golf, figure skating, gymnastics, and diving where the timing of the performance is under the control of the athlete, are more amenable to the use of key words than sports like hockey, basketball, and football, where the action is extremely fast paced 
and includes reactions to opponents" (p. 86). Although the practice of self-talk may be more complex with team sports, Thomas and Fogarty (1997) and Silva and Weinberg (1984) stress the importance of tailoring cognitive interventions to specific sports for effective performance outcomes. An extension of this research to team sport can help to expand promising developments in the area of self-talk.

In summary, we are aware that human thought is an ongoing process that requires attention and persistence to maintain its control. With the proficiency to become aware of our thoughts, we create the ability to alter and manipulate what it is we desire to conceive. This cognitive ability to reconstruct thinking patterns provides athletes with the capability to consciously create a positive athletic experience. Thinking can be a great benefit to performance, the key is knowing what, when, and how to think (Bell, 1983).

Self-Talk: A Behavioral Analysis

Self-talk is considered the underlying key to cognitive control. By narrowing internal stimulus control athletic skill can come under the control of a specific internal cue (Martin, 1997). Relating the skill through prompt recognition (i.e., cue word) enables a person to become more familiar with the control of the skill (i.e., a sprinter thinking "explode" as he or she starts a race associates leaving the starting block with a burst of energy). The establishment of a repetitive approach to performance (continuous use of self-talk) has the potential to lead to a consistency in performance. Albinson and Bull (1998) indicated that "repeated use of such statements causes them to be implanted in the unconscious mind" (p. 55). The development of specific practice routines stores sensory information that can be 
recalled by athletes in order to carry out actions appropriate to the sport situation (Kremer \& Scully, 1994). These competitive routines are "the plans for mental activity that the athlete establishes in order to focus attention and control thought content in performance" (Albinson \& Bull, 1998, p. 85).

Self-talk acts as discriminative stimuli for the appropriate behaviors during implementation of athletic skills. The cue words that comprise self-talk serve as "prediction keys which could activate programmed responses" (Moran, 1996, p.92). These programmed thoughts also reduce the occurrence of distracting thoughts that have the potential to diminish performance. The logic is that "the mind can only concentrate on one mental target (or idea) at a time, one cannot simultaneously focus on an instruction to perform some specific action and engage in self-destructive worry at the same time" (Moran, 1996, p. 73).

Research on Self-Talk

Descriptive research indicates that athletes use self-talk in both practice and competition in a multitude of ways. Self-talk can be used to aid athletes in learning skills, correcting bad habits, preparing for performance, focusing attention, creating the best mood for performance, and building confidence (Bunker et al., 1993; Williams \& Leffingwell, 1996).

The nature of self-talk for skill acquisition should differ as novice athletes become more proficient with their athletic abilities and skills. This hypothesis is related to the differences between the level of mental skills of beginners and experienced performers in the type of attentional processes they use. Bunker et al., (1993) suggest that "During early learning, skill acquisition is usually aided when 
self-instructional talk is used to remind the performer of certain key aspects" (p.227). This aid is done by the selection of a cue word or words that are associated with the specific skill or movement. For example, a basketball player saying "step, up, and release" when doing a lay-up or a swimmer saying "reach, push-down" for a specific stroke. These simple cue words are designed to foster cognitive associations that help the athlete learn and physically execute the skill precisely. There is a shift in the focus of self-talk from the mechanics of techniques towards the strategies and desired feelings associated with the skill, as the athlete gains experience. Cues such as "steady and hold" for a gymnast after a dismount or "light, feathery, and float" for a ballerina dancing through the air, help to trigger the desired, automatic action.

Proficient athletes can also use self-talk to change their bad habits. Landin \& Hebert (1999) corroborated that self-talk prompted the correct movement and also remediated movement pattern errors in skilled tennis players. The athletes felt that self-talk was related to their improvement because it heightened awareness and helped maintain proper attentional focus throughout performance. In scenarios dealing with behavior altercation "the athlete must unlearn an automatic response that is no longer effective and replace it with a new one" (Bunker et al, 1993, p. 228). According to Williams and Leffingwell (1996) self-talk can help to consciously override the automaticity of the bad habit to help further new responses. Self-talk that attempts to change previous learned techniques, must focus on the new desirable movements and not draw attention to the unwanted techniques. Hardy, Jones, \& Gould (1996) state "the importance of being able to identify inappropriate self- 
statements and thought patterns and restructure them is recognized as an important psychological skill in the applied sport psychology literature" (p.36).

Self-talk is also used to help athletes focus their attention during practice and competition. It is easy for an athlete's attention to wander and cue words are used as self-focusing statements to regain concentration. Weinberg \& Gould (1995) define concentration as consisting of two components; focusing attention on the relevant cues in the environment and maintaining that attentional focus. Bunker et al., (1993) stress the importance of using self-talk to focus attention in the present moment. By focusing on the present an athlete is focusing on what is under their control, as the past cannot be relived and the future cannot be predicted.

Self-talk has furthermore been used to help create a specific mood or effect. Rushall (1979) explains this phenomena by observing that when an individual thinks of self-commands that mean quick actions, the end result is the actions are actually speeded up. "Mood statements are the thought control mechanisms in the competition which maintain or develop the appropriate psychological state and they serve to arouse the athlete to the appropriate performance quality when required" (Rushall, 1979, p.92). He stresses that the main point behind the effectiveness of affective cues is that they must have direct movement counterparts. Selecting affective cues that are associated with the desired response helps toward achieving optimum performance. The intensification of attentional control has aided endurance runners in obtaining greater persistence and helped them to cope with stressors and pain throughout the distance (Weinberg et al., 1984). 
Self-statements also have a direct connection with an individual's selfperception or self-efficacy (Weinberg, 1985). Self-efficacy is defined "as the strength of one's conviction that he or she can successfully execute a behavior required to produce a certain outcome" (Silva \& Weinberg, 1984). The concept of self-efficacy represents a form of situation specific self-confidence where an individual has the belief they have the capabilities to attain a desired performance (Russell, 1993). Efficacy explanations influence athletic performance because "they determine how much effort athletes will expend on a task and how long they will maintain effort when confronted with setbacks and obstacles" (Bunker et al., 1993). Positive verbal persuasions utilized by the athlete have the potential to improve performance and overall self-confidence with regard to athletic abilities.

In order for self-talk to be most influential for athletes the cue words need to be carefully selected. Landin (1994) strongly promotes using the following guidelines for choosing cues: (a) brief and phonetically simple, (b) logically associated with the referent element of the skill, and (c) compatible with the sequential timing of the task. Brevity is crucial to reducing the risk of oververbalization. When athletes think excessively during a performance the end result is often 'paralysis by analysis' (Bunker et al., 1993). With this in mind, the selection of cue words should always be kept to a minimum. Secondly, the cues selected should foster a cognitive association related to the movement elements. "Blast" or "burst" are important cues in explosive movements that direct athlete's attention towards the significant components necessary for successful execution. Additionally, it is imperative to consider the 
rhythm or timing of the skill when selecting cue words in order to minimize the possibility of disrupting the flow of the performance.

It has been suggested by Palmer (1992) that coaches should be involved in the selection process of the appropriate key words used for self-talk. Many coaches at elite levels are familiar with the proper technical procedures that work best for their individual sport and have prior experiences with a variety of strategies to help skill acquisition. The present predicament is that "The coaches' expertise and knowledge is often overlooked or neglected when sport psychologists attempt to apply psychological principles or techniques to actual sport competition" (Weinberg, et al. \& Jackson, 1992, p.4). Involvement of the coaching staff has the potential to create increased interest for the coaches in the mental skill procedures to enhance performance of their athletes.

By identifying internal self-dialogue individuals come closer to understanding how they feel. Self-talk provides a useful method of organizing and directing thoughts. Finn (1985) expresses that one can accurately determine (a) how they feel, (b) what they are saying to themselves and (c) which body signals are providing information for personal evaluation. All of these components are significant to obtaining peak performance, a performance where the athlete puts it all together physically and mentally (Williams \& Krane, 1993). Tuning into the body and listening provides valuable insight with respect to what is being verbalized and whether self-talk needs changing. Techniques such as thought stopping and the cognitive restructuring techniques of countering and reframing are used to alleviate 
negative self-talk and enhance the occurrence of positive self-talk (e.g., Kendall et al., 1990; Bunker et al., 1993).

Thought stopping implies the interruption and stopping of ongoing thoughts. Athletes actively engage in the identification of disruptive thoughts, and use selfstatements as a trigger to stop and eliminate destructive thinking that is interfering with performance. Williams and Leffingwell (1996) state that "by stopping negative self-statements before they lead to negative feelings and behaviors, athletes experience relief from self-imposed negativity"(p.64).

Countering is a "process of internal debate - using facts, reason, and rational thinking to counter self-defeating thoughts" (Williams \& Leffingwell, 1996, p. 65). This technique is used to identify and counteract the belief of a negative selfperception with more positive and realistic self-statements. Negative thoughts are being challenged in an effort to transform self-defeating thinking into self-enhancing thinking. Bunker et al., (1996) accentuate the importance of believing in the positive statements. The ability to make a difference in the structuring of thoughts will only be effective if the athlete truly believes he or she can change.

An additional technique for confronting negative self-talk is known as reframing. This method enables athletes to change their perspective of how they confront a situation by changing their outlook. Bunker et al., (1996) proclaim that "reframing allows us to transform what appears at first to be a weakness or difficulty into a strength or possibility, simply by looking at it from a different point of view" (p.235). These techniques for controlling self-talk stem from an awareness of the negative thoughts we communicate and learning how to deal with them effectively. 
The practice of thought control is fundamental towards achieving a positive outlook towards performance. Finn (1985) puts it all into perspective by summarizing that "you can think about anything you wish. Control your mind; don't allow it to chatter on in nonsensical, self-defeating, upsetting thoughts" (p.70-71). The underlying premise is simply that the choice is up to the individual, whether they control their thoughts, or their thoughts control them.

The implementation of self-talk for performance enhancement proves to be a well received method for many athletes. Halliwell (1990) found professional hockey players to be very open-minded to self-talk techniques. From athlete's self-reports, Ming \& Martin (1996) discovered that figure skaters continued to use self-talk procedures one year after their study, as they believed the procedures improved performance. Athletes who report using self-talk in practice and competition have also been documented as having superior performances over athletes who do not believe in the utility of self-talk (Van Raalte et al., 1994). The type of self-talk used by divers has also differentiated qualifiers and nonqualifiers (Highlen \& Bennett, 1983). Qualifiers were found to use more self-instructions, whereas the non qualifiers applied more self-praise. Future research will help to further understand athlete's thoughts regarding the applicability of self-talk for improving performance.

Another area that would benefit from examination is the use of self-talk for performance enhancement in competitive situations. Implementing self-talk during actual competition might provide the most beneficial results (Landin \& Hebert, 1999). Most studies indicate an improved performance during the practice environment, but overlook the effects in relation to the competitive situation (e.g., Palmer, 1992; 
Thomas \& Fogarty, 1997; Weinberg et al., 1992). These real life competitive athletic situations interest coaches and athletes the most (Kendall et al., 1990), as performance in the competitive environment holds more merit than performance in a practice situation. Further examination should investigate whether the beneficial results of self-talk are "transferable" to a game or competitive situation.

Defrancesco and Burke (1997) express an interest in having more performance enhancement research performed with younger athletes. They propose that the average age of the elite athlete is decreasing, therefore more effort should be exerted on examining the impacts of mental skills for performance enhancement within these age categories. If future athletic success depends on the performance of the upcoming youth, it would be fruitful to expend efforts in researching how to maximize their performance.

It would also be advantageous to execute research that investigates self-talk with athletes participating in a diverse group of sports. Typically the classifications of athletics selected for research purposes involve individual, closed skilled sports, such as golf, figure skating, diving, etc., where the execution of the skill is under the control of the athlete (e.g., Highlem \& Bennett, 1983; Kirschembaum et al., 1998). Open-skill sports and team sports need to be considered, as for the most part they have been neglected in mental skills research (McPherson, 2000).

An additional domain that should be more carefully considered is the validity of the self-talk research. Research has relied on the athlete's self-reports of their application of self-talk. Results would possess enhanced internal validity (the independent variable did in fact cause observed changes in the dependent variable) if 
self-talk could be objectively observed. Suggestions such as having the athletes say the key words out loud have validated proof that the self-talk was truly occurring (Ming \& Martin, 1996; Palmer; 1992).

A substantial portion of the self-talk research, incorporates the use of other mental techniques with self-talk for performance enhancement. Ming and Martin's (1996) research with figure skaters included the use of a self-talk package that involved doing off ice walkouts of the figures, and then adding self-talk to help the skaters concentrate on the important components. Palmer (1992) used a similar package that involved the tracing of figures by skaters and the addition of selecting key words to help the skaters as they worked through the figures. Kendall et al., (1990) used a multi-element mental skill package to examine basketball game performance. The study investigated the effects of the combination of imagery rehearsal, relaxation, and self-talk on the performance of a defensive basketball technique. Kirschenbaum et al., (1998) have gone one step further by tailoring a cognitive intervention package specifically for golf that includes five different components; preparation, positive focusing, planning, applying and reacting. The results of these studies indicated that athletic performance improved, but it is difficult to attribute directly how much of the participants successes were related to the selftalk alone. Research that isolates self-talk as the only mental skill training mechanism can help to validate the specific effect of self-talk on enhancing performance.

\section{$\underline{\text { Summary of Research }}$}

Research has demonstrated that self-talk can be used to help athletes learn skills, correct bad habits, prepare for performance, focus their attention, create 
performance moods, and build confidence. Self-talk that is brief, directly related to the elements of the skill and compatible with the timing of the skill has proved to be most influential for athletes. Cognitive restructuring techniques such as thought stopping, countering and reframing are all methods to enhance the occurrence of positive self-talk. Athletes have responded favorably to the implementation of selftalk for performance enhancement. Although self-talk has been well received by many athletes, there is still a need to develop a broader base of research that includes athletes of different ages, athletes in different sports and athletes performing in the competitive environment.

\section{Statement of the Problem}

This study examined a specific skill in soccer, the low drive shot (See Appendix A). The low drive shot was selected as it is an effective scoring mechanism in the game of soccer. Aiming for the lower corners is the best shot for outdoor soccer (Luongo, 1996), making it an important skill to learn and master. According to Saunders (1974), priority in skill development with soccer players should be on kicking. "Mastery of kicking is vital, because this is what the game is all about. A poor kicker can do nothing to hide his weakness no matter how good he is in other departments of the game" ( Saunders, p.28). Bailey and Teller (1970) agree that kicking is the whole basis of the game, but kicking must be controlled and have purpose. There is a component of concentration behind effectively kicking a soccer ball that includes a combination of power and accuracy and knowing the right mixture of both (Hughes, 1980). 
The importance of the kicking skill is directly related to 'putting the ball in the net', which is the overall idea behind the whole game of soccer (Canadian Soccer Association, n.d.). Making kicking a priority is also relevant since a major concern in modern soccer is the lack of goals. Defensive strategies over the past couple of decades have become more efficient resulting in increased difficulty in putting the ball in the net (Canadian Soccer Association, n.d.). Although the scoring of goals is the overall objective of the game of soccer, the number of shots that end up in the back of the net is sparse. Beim (1977) suggests that if one out of every nine shots on goal results in a goal your team is attaining a satisfactory performance. The secret to goal scoring is much sought after, and an ability soccer players desire to acquire. The art of shooting appears to coincide with the ability to maintain concentration. "More often than not, when a shot on goal is poor, it is more a result of poor concentration than of poor kicking ability. The greatest physical and mental pressure of the match comes down on the players while they attempt to shoot and score" (Beim, 1977, p. 285).

Athletes need to determine the most important components to focus on in a given sport situation. Moran (1996) suggests "zooming in" on selective cues that provide the greatest amount of specific, task relevant information. Self-generated instructional commentary that accommodates this concept could help athletes stay focused on what is important at the moment to carry out the skill. The concept of training soccer players to use self-talk as a focusing technique to clear the mind of irrelevant thoughts that interfere with shooting performance has promise to help athletes in the scoring department. 
This study assessed whether self-talk is an effective intervention for improving soccer shooting performance in practice and competition. The present study further extends research that examines the effects of self-talk on the performance of skilled athletes. Similar to the Landin \& Hebert (1999) study, the purpose of this study was to extend the findings of the effectiveness of teaching skilled athletes to use self-talk and to gain insight on the athlete's perceptions of selftalk and how it influences their performance. This study replicated methods used by Landin \& Hebert (1999), and incorporated many of the concepts that have been lacking in research on self-talk, including working with younger athletes, assessing both practice and competitive results and in particular, working with a team sport. By working with a population that has received limited research attention, an effort was made to enhance performance with a group that has less exposure to self-talk techniques. Specific mental skill techniques, adapted solely with the sport of soccer in mind, would be most advantageous for research in this area.

\section{Method}

\section{Participants}

Four female soccer players from the under fourteen (U-14) female Manitoba Provincial soccer team participated in the study. The four athletes were all members of the training squad for the 2001 U-14 Provincial team. The training squad consisted of 30 athletes who were training to be selected for the final 18 players who would represent the Province in their age category. The process of team selection was carried out over a five month winter training program and the outdoor training sessions held by the Manitoba Soccer Association. At the end of the training camps, 
the coaching staff selected a roster of eighteen players who they believed were the "best" individuals for the team.

The four participants were selected by the coaching staff using the following criteria: a) they played a position that does a lot of shooting on net in games (e.g., a striker, or an attacking central midfielder), b) the head coach thought these athletes had the promise to execute the low drive shot, but did not demonstrate the skill effectively in the training sessions, and, c) the athletes had a high likelihood of making the team, as the squad training consisted of 30 athletes trying out and the team would only consist of 18 players.

The four athletes all resided in the province of Manitoba and their mean age was 14 years. The participants had a mean 6 years of soccer playing experience. Playing experience was defined as being part of a formally organized team that was registered with the governing association (e.g., Winnipeg Youth Soccer Association Inc.). The participants were all familiar with the skill that was introduced to them, the "low-drive shot", but had not mastered the low-drive shot prior to the study.

Informed consent was gained from all of the participants, and their parents/legal guardians to participate in the study (Appendix B and C). Authorization to work with the team was given by the coaching staff of the U-14 Provincial team and the governing association, the Manitoba Soccer Association. Ethical approval of the study was also given by the University of Manitoba.

\section{Experimental Design}

A single-subject multiple-baseline across-individuals design was used to examine the effects of the intervention on the performance of the low-drive shot in 
practice and competitive situations. The single-subject design was used as this design has numerous features that are appropriate for research in athletic situations (Hrycaiko and Martin, 1996). Wollman (1986) indicated "single-subject designs... allow detection of successful effects for certain individual subjects who otherwise might have their success masked in a non significant group design (p. 136)." Furthermore, "small but consistent changes may be seen in a single-subject design but not emerge significantly in a group design (Wollman, 1986, p.136)." Bryan (1987) also stated "this design permits the intensive investigation of athletes who have a specific performance disorder, thus eliminating the problem of group averages and any lack of statistical significance obscuring improvements in individual performance" (p. 284).

Wanlin, Hrycaiko, Martin, \& Mahon (1997) indicated that single-subject research designs further "lend themselves to combining both objective and subjective measures of performance (i.e., visual assessment of behavioral observations of dependent variable(s) and social validation of results through self-report) (p. 214).” The use of a single-subject design also eliminates the need for a no-treatment control group, which can be viewed as unethical or unacceptable by coaches and athletes who want every opportunity to excel and improve (Bryan, 1987). This design allows continuous monitoring of athletic performance in both practice and competitive situations providing valuable information for coaches and athletes. Dependent Variable

The dependent variable was the athlete's performance of the low-drive shot in both the practice and competitive settings. Low-drive shot performance was assessed 
by observers throughout twelve practice sessions and five competitive matches. Fifteen shots were taken per practice session and the number of shots observed in the competitive sessions varied from game to game.

The number of correct low-drive shots was determined by totaling the number of accumulated points. For example, if one of the athletes scored 15 with a possible total score of 30 , her score of correct low-drive shots would be 15 . The higher the score indicated greater success with the low-drive shot.

\section{$\underline{\text { Assessment Drill }}$}

A drill was designed in conjunction with the coaching staff to practice the players low-drive shooting. The drill required the athletes to take a series of three low-drive shots on net. The "mini-nets" were set up in the bottom left and right hand corners of the goals along the goal line in the net. These "mini-nets" served a dual purpose; they provided a visual target for the shooters to aim for when shooting and secondly, they provided the observers with a simplistic manner to assess performance (i.e., did the shot go in the "mini-net"?).

The athletes began the drill just inside the top of the 18 yard box and were fed a three shot sequence by an assistant (see Figure 1). The balls were placed in an arch around the top of the "D" on the soccer field. Each player began the sequence by facing the direction of the server. Starting from the server's left hand side, the balls were fed approximately to the feet of the players. Each player was permitted a maximum of two touches on the ball. One touch to control and turn with the ball to face the net (if necessary), and a second touch to be the low-drive shot on net. The player then returned to the starting position and received the next ball, until the three- 


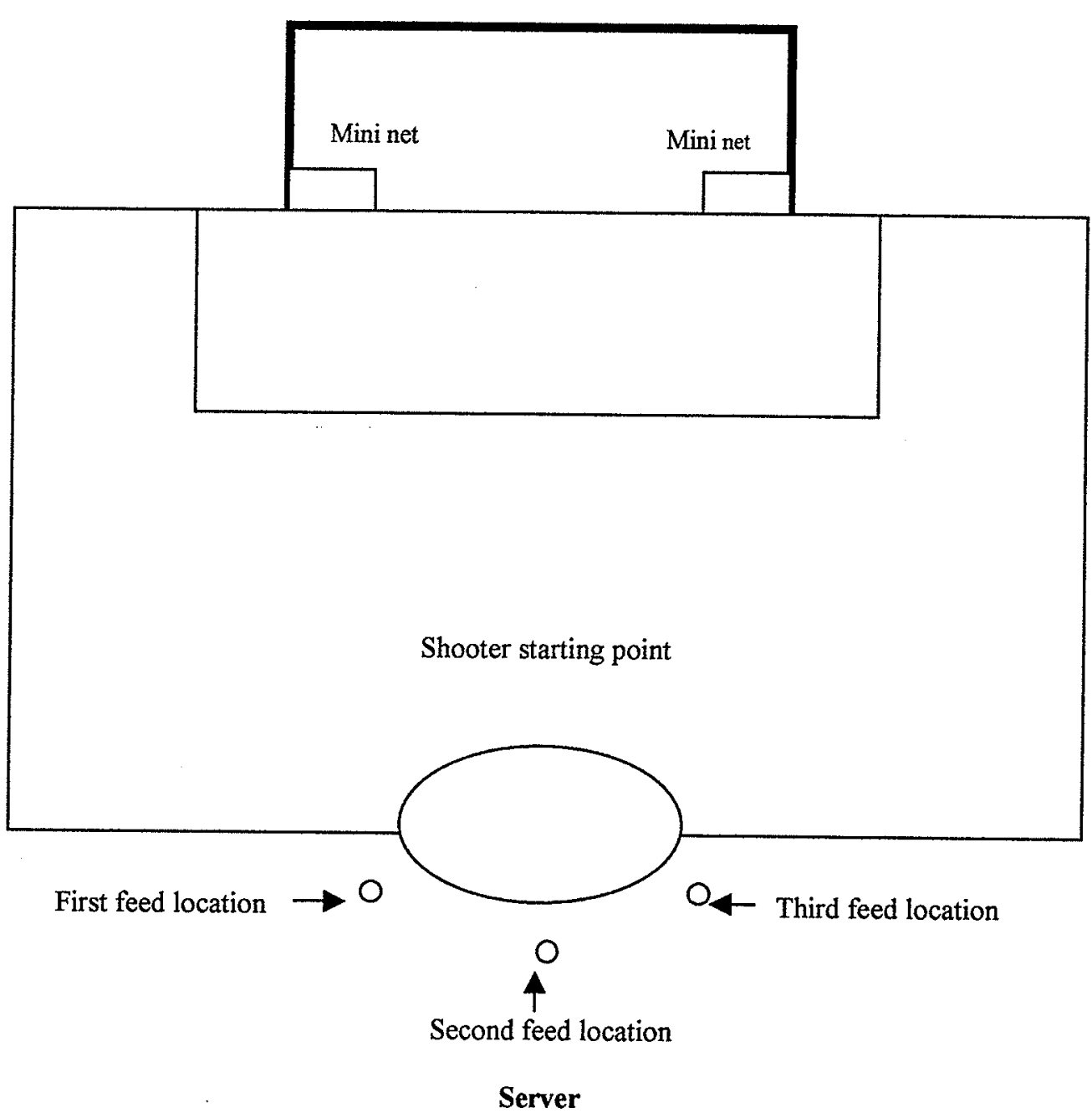

Figure 1. Layout of the low-drive drill 
ball sequence was completed. The player then immediately restarted the sequence and completed four additional repetitions, for a total of five repetitions. A total of fifteen shots was taken by each player at each practice session $(3$ shots $\mathrm{x} 5$ repetitions $=15$ shots).

In an attempt to make the drill as realistic as possible, several factors were implemented into the drill. First of all the athletes were instructed to execute the drill at a "game-like" pace; they were running and sprinting to the ball throughout the drill. Secondly the players started out by facing the server and then turned to shoot. The turn was implemented because, for the most part, in a game situation the shooter will have to turn to some extent towards the net to shoot. Thirdly, the participants did the drill near the end of each practice session to incorporate fatigue as a factor in the shooting. Lastly, the three different locations of the balls being fed into the shooter required the shooter to take different shooting angles on net, and ensured the possibility of using both of their feet when shooting.

\section{Treatment Variable: Self-Talk Strategy}

Prior to the intervention phase, the individuals were introduced to the concept of self-talk through a meeting with the experimenter (Appendix D). The participants were made aware of self-talk and interviewed about their self-talk behavior. The interview was used to determine whether the athletes currently used self-talk and to determine to what extent they have used self-talk. It was necessary to determine the history of the athlete's use of self-talk, as athletes could already be using self-talk while shooting. The athletes were then taught the two-word self-talk sequence. The words selected by the coaching staff were "down" and "lock". The words are cues on 
how the proper technique of the low-drive is implemented. To successfully accomplish the low-drive, the ankle needs to be locked for a strong impact, and the foot needs to be pointed down towards the ground in order to obtain proper ball trajectory.

The athletes were instructed to use these words every time the skill was implemented. The participants were told to use the words in a two word-sequence "downlock", as first they needed to get their body over the ball with their toes pointed down and then needed to lock the ankle to effectively strike the ball. The athletes were asked to engage in the self-talk internally by saying the words in their heads, so the other participants were unaware of their behavior. It was also stressed to the athletes not to discuss the intervention with other participants to avoid contamination effects. If the athletes informed the other participants of the self-talk cues while they were in baseline, the potential for their performance to be influenced existed if they implemented the self-talk on their own prior to intervention.

\section{Setting and Apparatus}

During the practice sessions data were collected at the training site, an outdoor grass soccer field, 110 yards x 65 yards, during scheduled sessions from 6:30 p.m. to 8:00 p.m. on Fridays and 10:00 a.m. to 12:00 p.m. on Saturdays. A standard soccer net 8 feet high and 24 feet wide was used for all low-drive shots. Miniature nets made out of plastic tubing, 2.5 feet high $\times 4$ feet wide, were placed in the bottom right and left corners of the standard soccer nets and used as targets in practice settings only (See Figure 1 for the position of the mini-nets). These miniature nets were placed and pegged down on the goal-line along side each goal post. Size five soccer balls were 
used for all shooting in the study. Data were collected during baseline and intervention phases in the practice setting.

A standardized recording sheet was given to the observers to document the location of the shot, and to rate on a point scale from 0-2 the end result of the shot on the recording sheet. A score of 0 indicated the shot was off-target (not to the bottom corners), a score of 1 indicated the ball hit the miniature net within the net (i.e., post, crossbar), but did not go in the mini net, and finally a score of 2 indicated the shot went into the mini net (see Appendix E).

Data from competitive settings were collected at the sites of the games. The games played were part of a season ending tournament. The tournament occurred after all practice session data had been compiled. These settings were all typical, standard soccer fields, with the dimensions similar to the practice field.

A slightly different recording sheet was used in the competitive setting, as the use of the miniature nets ceased (Appendix F). The mini-nets were not permitted during matches, according to FIFA (Federation International de Football Association), the governing association of soccer.

Prior to the initiation of the study and after the study, players responded to a brief survey to investigate their sentiments towards their low-drive shooting in competition. Following Landin \& Hebert's (1999) study, the low-drive performance survey consisted of three components; assessing how confident athletes were in scoring goals with the low-drive shot in games, how often they aimed for the low corners in games, and how effective their low-drive shots were in games (See Appendix G). 


\section{Personnel}

Behavioral observations were taken by two members of the team. All observers underwent a training period until inter-observer reliability was established prior to the data collection. These practice sessions provided the observers with a chance to learn the recording protocol, familiarize themselves with the recording sheets, ask the experimenter questions, and practice recording "mock" trials, with the experimenter acting as the participant (Appendix $\mathrm{H} \& \mathrm{I}$ ).

A third member of the coaching staff, who was a skilled soccer player, was selected to feed the balls to the participants. This individual was trained for the drill and provided "feed targets" to direct the passing of the soccer balls to the participants.

\section{Procedural Reliability}

Procedural reliability is the assurance that a particular intervention was applied as intended and as described (Hrycaiko \& Martin, 1996). Prior to the intervention phase all participants were introduced to the concept of self-talk through a scripted meeting with the researcher (see Appendix D). Each participant met at the training field with the researcher prior to the commencement of the practice session that the intervention was to be administered. At this time the participant was made aware of self-talk, interviewed about their self-talk behavior, and taught the two-word self-talk sequence following the interview script. Preceding the assessment drill in the intervention phase, each participant was "cued" by the researcher to employ the selftalk. Prior to each practice session the researcher cued each of the athletes to use the self-talk strategy. 
Prior and post intervention the participants also completed the low drive performance surveys in the presence of the researcher just in case any questions/misunderstandings would arise.

\section{Procedure}

All experimental procedures were incorporated into the team's normal practice routine and game schedule. Data collection occurred over a three month period during the outdoor training season.

Baseline.

Performance assessments occurred at every practice session that the individuals were in attendance. Observers recorded the performance of the athlete's low-drive shot for all fifteen of the participant's shots at each session on the recording sheet. For each shot the observers indicated an " $\mathrm{X}$ " on the diagram of the net as to the location of the shot, and circled the rating from 0 to 2 on the recording sheet. Assessments took approximately 16 to 20 minutes each practice, with each participant's turn taking roughly 4 to 5 minutes. Baseline data continued to be collected until the data was stable or in the opposite direction hypothesized as a result of the intervention.

At this point the first individual was introduced to the concept of self-talk, through an informal meeting with the experimenter. During this consultation they were made aware of self-talk, interviewed about their self-talk behavior, and taught the two-word self-talk sequence. They were also given the brief survey regarding their low-drive shooting. Each participant underwent the same process prior to intervention. 


\section{Intervention.}

When the baseline was established, the first participant began the intervention phase, while the remaining participants continued on baseline. The participant was instructed to use the two-word self-talk sequence for every low-drive shot they executed. They continued to go through the same fifteen shot sequence as in baseline while implementing the self-talk. Every second session one participant began intervention, with the remaining participants following in proceeding sessions. The final participant remained on baseline for the duration of the study to control for possible training effects. Intervention was administered to this participant after the study was completed. The participant was made aware of the procedures the other participants had undergone.

Performance assessment followed the same format as during baseline sessions. In addition, the observers assessed the participants shooting in competitive situations (tournament matches). Assessment was carried out as described in Appendix F, with observers evaluating how many shots the participant took, how many of them were low-drive shots, and how many they scored on.

\section{Follow-up.}

At the termination of the study each participant and the coaching staff were interviewed by the experimenter. The participant interview (see Appendix J) focused on four issues: (a) past experience and use of self-talk, (b) verification of their use of the two-word self-talk strategy, (c) perception of the strategy's effectiveness, and (d) insights and explanations on the function of self-talk (Landin \& Hebert, 1999). The coaching staff was surveyed regarding the participant's performance in relation to the 
last two issues (see Appendix K). The participants were asked to complete the lowdrive performance survey to assess their beliefs regarding their ability to perform the low-drive shot. All responses from the participants and coach were hand-recorded by the experimenter.

Treatment of the data

Two independent coders assessed low-drive performance in practice and competitive settings. Inter-observer agreement (IOR) for each variable was calculated by dividing the lowest number of agreements by the highest number of agreements of the low-drive performance, and multiplying the dividend by $100 \%$. IOR of at least $80 \%$ was obtained prior to the study as recommended by Kazdin, 1982. IOR's were calculated at three different intervals throughout the study to ensure IOR's exceeded $80 \%$.

Performance assessment in practice and competitive sessions are displayed graphically. The data were assessed according to the following guidelines; "(a) when baseline performance is stable or in a direction opposite to that predicted for the effects of treatment; (b) the greater the number of times that an effect is replicated both within and across individuals; (c) the fewer the overlapping data points between baseline and treatment phases; (d) the sooner the effect is observed following the introduction of treatment; (e) the larger the effect in comparison to baseline" (Wanlin et al., 1997, p. 218).

The study also assessed social validity through the brief surveys and interviews given to the athletes and coaches. Social validation refers to the evaluation 
of the practical significance of the study (Wolf, 1978). A social validity assessment involves asking three questions (Hrycaiko \& Martin, 1996):

1. To what extent are the target behaviors identified for the treatment programs really the most important for the participants and society?

2. Are the particular procedures used acceptable to the participant, especially when alternative procedures might be available to accomplish approximately the same results?

3. Are the consumers of intervention (participants, coaches, parents) satisfied with the results obtained?

Results from the interviews with the participants and coach, and results from the brief low-drive performance surveys are presented as quantitative data. The lowdrive performance surveys provided data regarding the athlete's perception of their low-drive shooting ability prior to the intervention and at the completion of the study. This procedure provided pre and post data comparison with insight as to whether the intervention changed the participants' belief in their low-drive shooting ability and whether they thought the low-drive was an important skill to devote extra practice towards.

The participant interview and coaches' interview provided an opportunity to obtain thoughts with regard to whether the participants and coaching staff believed the intervention was effective in improving performance, whether self-talk was an acceptable method for improving the low-drive shot, and to learn whether it was important to improve their low-drive shots. 


\section{Results}

\section{$\underline{\text { Reliability }}$}

The IOR checks were implemented three times throughout the duration of the study. IOR scores of $80 \%$ or greater are considered acceptable (Kazdin, 1982). The IOR checks on the dependent variable throughout the baseline and intervention phases demonstrated that the observers were in $100 \%$ agreement throughout the study.

\section{Intervention Effects}

The participants total points accumulated for low-drive shooting were plotted and visually examined (see Figure 2). The data was visually analyzed in accordance to established guidelines to determine the effects of the intervention. The guidelines were as follows: (a) baseline data is stable or descending, (b) little or no overlap of data points from baseline to intervention, (c) immediacy of change from baseline to intervention, and (d) size of the change from baseline to intervention (Hrycaiko \& Martin, 1996). Table 1 provides the means for all of the participant's low drive shooting points accumulated in both baseline and intervention phases.

Visual inspection of the athlete's performance on the low-drive shot disclosed that all three participants who received intervention had descending baselines, heading in the direction opposite than hypothesized for intervention (Figure 2). In addition to descending baselines, participant's 2 and 3's data was also relatively stable during this phase.

Two of the participants displayed an immediate effect when the self-talk strategy was implemented. Participant 1 was the first to receive the self-talk 
intervention after the $4^{\text {th }}$ practice session. The participant's shooting improved from a mean of 4.5 in baseline to a mean of 6.5 following intervention, but did not demonstrate an immediate change following the commencement of the self-talk intervention. Performance continued to fluctuate with numerous overlapping data points, until the last three practice sessions where performance began to increase and stabilize.

Participant 2 received the intervention after the sixth practice session. This participant displayed an immediate effect when intervention was initiated. The participant's performance continued to increase throughout the intervention phase with the exception of one data point. This participant also disclosed no overlapping data points across phases. An increase in low-drive shooting from a mean of 5.3 during baseline to a mean of 10.5 after intervention was demonstrated.

Participant 3 was the final participant to receive intervention. The self-talk strategy was administered to this participant prior to the eighth practice session. This participant displayed the most significant intervention effect with performance increasing from a mean of 4.4 in baseline to a mean of 12.3 following intervention.

Immediacy of change from baseline to intervention was most apparent for this individual. At the time of intervention low-drive shooting performance increased $27 \%$. All subsequent data points continued at a level greater than the highest point in baseline conditions. Improvement on low-drive shooting performance continued throughout the duration of the study with the participant shooting at a higher 
Baseline Intervention
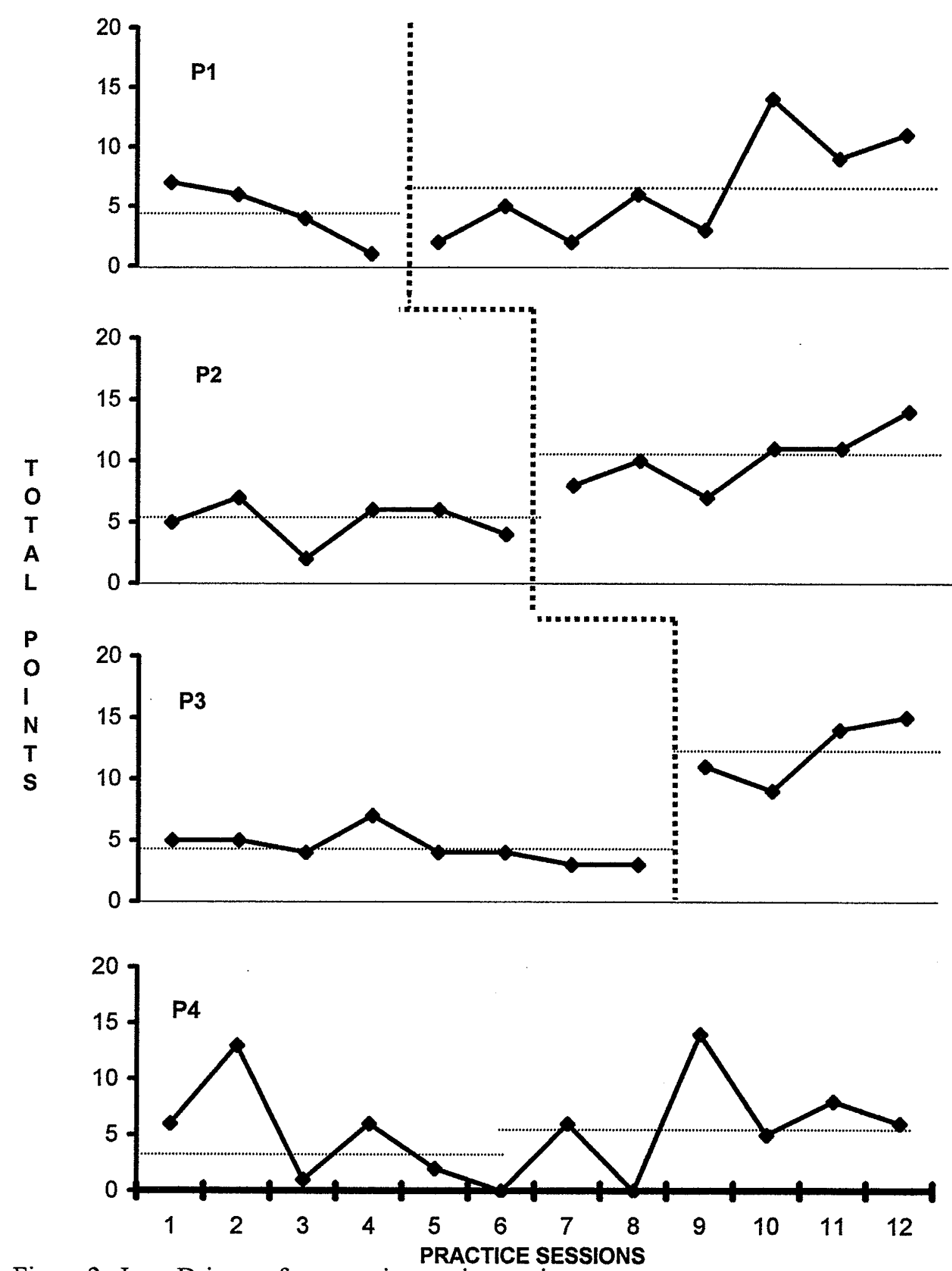

Figure 2. Low-Drive performance in practice sessions 
level for the remainder of the season.

Participant 4 was not an experimental participant and remained in baseline for the duration of the study. This final participant was solely assessed for a training effect determined by dividing the practice sessions into two equivalent parts. Examination of the participant's early data in comparison to the second half of the training sessions demonstrated a small training effect. The later baseline mean performance was 1.8 points higher than the earlier mean performance, indicating a slight improvement in low-drive shooting performance. This participant did not develop any other trends with the data collected, as data points demonstrated considerable variability, and there were numerous overlapping data points between the early and later phases of the study.

Table 1

Mean of Low-Drive Shooting Scores During

Baseline and Intervention Phases

\begin{tabular}{lll}
\hline Participant & Baseline & Intervention \\
\hline 1 & 4.5 & 6.5 \\
2 & 5.3 & 10.5 \\
3 & 4.4 & 12.3 \\
4 & 4.7 & 6.5 \\
\hline
\end{tabular}

Note. Participant 4 did not receive intervention. The $M$ and SD are taken from first and second half of baseline performance. 


\section{Game Performance}

A second component of the study involved the assessment of the participants shooting behavior in competitive game situations. Performance was assessed over five games throughout a tournament that the team attended. This tournament was the only competitive situation that the team was able to participate in, and was a season ending tournament. Table 2 is a compilation of each of the participants' shooting performance in the competitive settings. The recordings of the participants' shooting revealed that all three experimental participants $(1,2$, and 3 respectively) averaged $79 \%, 83 \%$, and $72 \%$ low-drive shots per game. All of their goals scored were by lowdrive shots, with the exception of participant 2 who did not score a goal throughout the competitions. Participant 4 who did not receive the intervention shot $57 \%$ of her shots using the low-drive technique, with $63 \%$ of her goals resulting from low-drive shots.

The participants (1,3, and 4 respectively) scored $7,3.7$, and 2.9 goals per every shot they took. Their low-drive shots per low-drive goals scored were 5.5, 2.7 and 2.6.

Throughout the duration of the competition participant's 1,3 , and 4 played the position of strikers with participant 2 playing as an attacking midfielder. Playing time was monitored by the head coach and kept as consistent as possible across players, therefore all four of the participants in the study were on the field for more or less the same duration of time. 
Table 2

Shooting Assessment in Competitions

\begin{tabular}{lllll}
\hline Participant & 1 & 2 & 3 & 4 \\
\hline Shots taken & 14 & 6 & 11 & 23 \\
LD shots taken & 11 & 5 & 8 & 13 \\
Goals scored & 2 & 0 & 3 & 8 \\
LD goals scored & 2 & 0 & 3 & 5 \\
Goals per shots & 7 & N/A & 3.7 & 2.9 \\
LD goals per LD shots & 5.5 & N/A & 2.7 & 2.6 \\
\% of LD shots & $79 \%$ & $82 \%$ & $72 \%$ & $57 \%$ \\
\hline
\end{tabular}

Note. $L D$ is abbreviated for low-drive

Surveys

The results from the pre- and post-intervention low-drive performance surveys indicated that the participants' perceptions of their low-drive shooting ability increased after the experiment (see Figure 3). Confidence in their ability to score goals with the low-drive shot increased from a pre-intervention mean of 3 to 4 after the experiment. The frequency at which the participants aimed for the low corners when shooting likewise improved from a mean of 3 to 3.6. Similarly, the perceptions of effectiveness of scoring goals with the low-drive shot rose from a mean of 3.81 to 4.

\section{Social Validation by Participants}

The experimental participants $(1,2$, and 3$)$ responded to pre- and postintervention questions regarding their use of self-talk. Prior to intervention the 


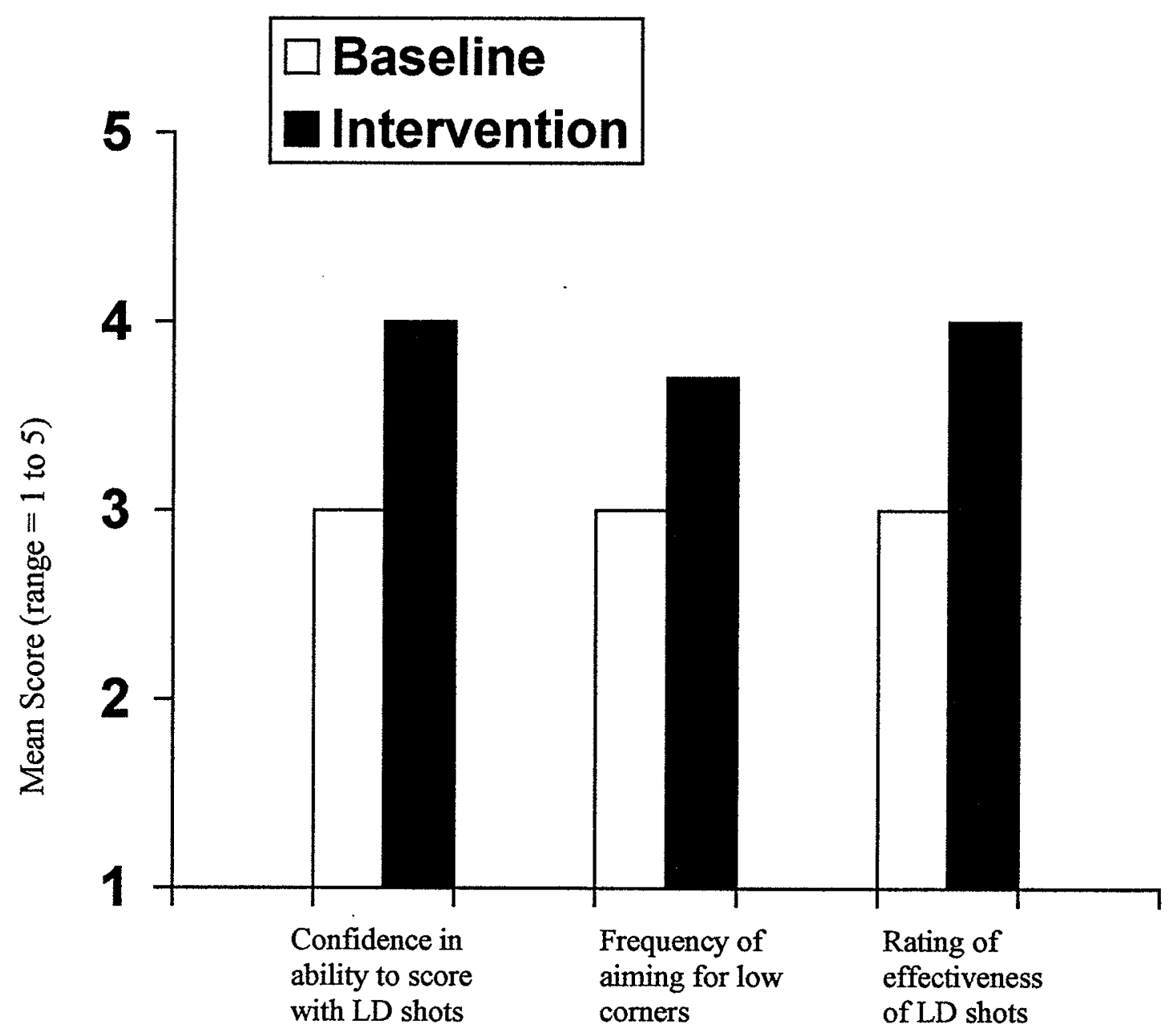

Figure 3. Pre- and post-intervention perceptions of $L D$ shooting ability for experimental participants $(1,2$, 3) 
knowledge and level of self-talk was assessed for each participant. It was determined by the pre-intervention interview with the participants, that the athletes understood the concept of self-talk for performance enhancement, but felt they had not engaged in implementing self-talk into their practice and game routines. They recalled times where they used positive or negative self-statements (e.g., participant 2 and 3 thinking "don't miss the net", or participant 1 saying "that shot stunk"), but had never formally utilized self-talk to improve performance.

The participants unanimously agreed that improving their performance of the low-drive shot was very important. All three felt that increasing the consistency of their low-drive shooting was an important component of becoming an effective goal scorer. When asked about the effectiveness of using a self-talk strategy to improve low-drive shooting performance, all three participants believed that this method could help with their performance.

Post-experiment interviews were employed to elicit validation checks on the participants' use of the two-word self-talk strategy. All reported that they used the cue words the majority of the time during practice sessions. Participant 1 indicated she used the self-talk strategy approximately $75 \%$ of the time, while participants 2 and 3 applied the strategy $90 \%$ of the time. The participants confirmed that they continued to use the self-talk strategy in the competitive matches played. Participant 1 indicated "when I was shooting in games I thought about the cues", participant 2 revealed "I said to myself down \& lock when I got in front of the net", and participant 3 reported "I used the cues to help me shoot in games". 
When inquiring about their perceptions of the impact of self-talk on their lowdrive performance, all participants responded very positively indicating that the strategy had helped improve their low-drive shooting. The participants believed the self-talk strategy increased confidence (e.g., "It made me confident, I knew how to shoot, and that gave me confidence I would score more goals"), and helped them to focus their attention on the relevant cues (e.g., "I only focused on the things I was supposed to be doing"; "I thought about what I needed to do and did it"; "When I didn't use the self-talk, that's when I messed up").

The three participants were also very satisfied with the results produced from using the self-talk strategy. Participant 1 reported feeling "satisfied"; with participant's 2 and 3 feeling "very satisfied". In addition all three of the participants indicated that they felt self-talk would be beneficial for other athletes attempting to improve their shooting, and also with other skills and across other sports. The participants indicated they would continue to use the self-talk strategy to help them with their low-drive shooting and that using the self-talk strategy was an enjoyable experience.

\section{$\underline{\text { Social Validation by Coach }}$}

Of the two members of the coaching staff, the head coach was interviewed with regard to the study and the participants low-drive shooting (see Appendix K). Only the head coach was interviewed, as the other member of the coaching staff was the goalie coach, and he did not spend time with the field players.

The coach rated improving low-drive shooting very important for the team and noticed a difference in all but one of the participant's low drive shooting ability. 
He felt participants 1, 3, and 4 all improved their shooting and increased the percentage of low drive shots they took by $25 \%, 40 \%$, and $50 \%$ respectively. Although the coach did not perceive participant 2 to improve technically at the lowdrive shot, he felt she increased the percentage of low-drive shots she attempted by $10 \%$.

In addition the coach was asked to assess whether he felt the athlete's improvement in performance to be an important change. He confirmed that all enhancement of performance that the athletes demonstrated was important, but he was not cognizant of the increase in participant 2's performance.

\section{Discussion}

The present study continued a course of research that has examined the effects of self-talk on athletic performance (Landin \& Hebert, 1999; Rushall, Hall, Roux, Sasseville, \& Rushall, 1988; Van Raalte, Brewer, Lewis, Linder, Wildman, \& Kozimor, 1995; Van Raalte et al., 1994; Ziegler, 1987). The purpose of the study was to further extend the research on the effectiveness of teaching skilled athletes to use self-talk and secondly to gain insight on the athlete's perceptions of self-talk and how it influenced their performance. A two-word self-talk strategy was developed to focus on the key components of the low-drive soccer shot. The self-talk strategy was created using Landin's (1994) guidelines for developing self-talk. These guidelines stressed self-talk should be (a) brief and phonetically simple, (b) logically associated with the referent element of the skill, and (c) compatible with the sequential timing of the task. Research has demonstrated that the use of one or two simple cue words will not disrupt performance (Landin \& Hebert, 1999; Mahoney \& Avener, 1977; 
Madigan, Frey, \& Matlock, 1992). Task-relevant self-talk that focused on the technical aspects of the low-drive shot was used. This type of self-talk has been found to produce the largest gains in performance for cross-country skiers, in comparison to mood words or positive self-statements (Rushall et al., 1988).

A variety of different methods were utilized to collect data from the participants, including interviews, surveys, and the quantitative analysis of low-drive shooting. The effort to acquire qualitative, as well as quantitative data, responds to the appeal of Wanlin et al., (1997) for additional information to enhance our understanding of how athletes view objective and subjective measures of success. The combination of techniques demonstrated that the self-talk strategy was effective in improving low-drive shooting performance.

An evaluation of the experimental participants' performance throughout the study demonstrated that all of the participants improved their performance on the low-drive shot, although the degree of improvement varied. Studies that have secluded self-talk as the sole mental skill are limited in number and have dealt with sports other than soccer (e.g., Landin \& Hebert, 1999; Rushall et al., 1988, Van Raalte et al., 1994; Ziegler, 1987). These studies assessed self-talk in relation to enhancing performance in tennis or cross-country skiing. The results of the present study support previously reported research exploring the sole effects of self-talk on athletic performance.

The findings of the present study cannot be directly compared to much of the current literature in the area of self-talk as most studies incorporate self-talk in a mental skills training package. For example, Kendall et al's., (1990) results indicated 
that a combination of imagery rehearsal, relaxation, and self-talk were effective in enhancing the performance of a defensive skill in basketball game performance. Kirschenbaum et al, (1998) incorporated a mental skills approach to golf including preparing, positive focusing, planning, applying, and reacting which improved their scores, and increased emotional control, positive self-talk, and relaxation. Ming \& Martin (1996) used self-talk in combination with laying out figures and off-ice walkouts with figure skaters. They found noticeable improvements in skating performance, and continued use of the package one year later by the athletes. Patrick \& Hrycaiko (1998) demonstrated that a mental training package including relaxation, imagery, self-talk, and goal setting was effective in improving the performance of endurance runners. Finally, Thomas \& Fogarty (1997) concluded that the use of imagery and self-talk developed specifically for golf led to improvements in their mental approach to the game and their actual performance. Although these studies dealt with a combination of mental techniques, they were similar to the present study in enhancing the athlete's performance. The studies were all effective in improving athletic performance, but with the mental skills packages it is difficult to directly attribute the level of athletic success that is related to self-talk alone. The isolation of self-talk as the only mental skill in this study, validates the effect self-talk has on enhancing athletic performance.

The results of this study contribute to the research literature in various ways. Foremost the low-drive shot had not been examined prior to this investigation and furthermore, the sport of soccer has received minimal research. The examination of mental skills research with individual sports is much more common than with team 
sports (Martin, 1997). The only team sport included in self-talk research to date is basketball (Kendall et al., 1990), although Halliwell (1990) has reported that self-talk is effective with professional hockey players. The exploration of new skills and sports provides knowledge and information in areas that can be useful to athletes, and coaches beyond the typical individual, closed-skill sport studies (Kirschenbaum et al., 1998; Ming \& Martin, 1996; Palmer, 1992; Patrick \& Hrycaiko, 1998; Thomas \& Fogarty, 1997; Weinberg et al., 1984).

The study was unique in that it examined the dependent variable across practice and competitive situations. Very few studies (Kendall et al., 1990; Landin \& Hebert, 1999) have taken into account the competitive environment when assessing athletic performance. The present study adds to the literature by demonstrating the effectiveness of self-talk in practice and competitive situations while extending the findings to the sport of soccer. Although the athletes in this study were unable to play games prior to the intervention, due to the team's schedule, the data supported by qualitative information revealed that the athletes took more low-drive shots when shooting and felt more confident in their ability to execute the low-drive shot following intervention.

An interesting finding with this study was that there was a slight training effect detected for participant 4 throughout the time frame that data was collected. This finding is contrary to what has been reported in the current literature. Patrick \& Hrycaiko, (1998), Rogerson (1998), and Wanlin et al. (1997) found no convincing evidence that a training effect was apparent for athletes that continued in baseline and received standard coaching. Although this finding could possibly imply that continual 
physical practice alone is sufficient to improve performance, this may not be the case. Participant 4's practice performance improved when assessing early and later portions of the study, but the magnitude was very small. Of greater concern from a coaching perspective was that the participant did not develop any consistent trend with her performance demonstrating considerable variability throughout the study. According to the head coach this player was the best low-drive shooter of all the participants. A possible explanation of participant 4's variable performance was that she had the physical ability to obtain a superior performance, but she may have lacked the ability to concentrate on the necessary cues for consistent performance in practice. However, regardless of the reason, variability in the data with field studies is not uncommon (Kendall et al., 1990). In contrast to the baseline phase, studies (e.g., Kendall et al., 1990; Wanlin et al., 1997) have reported that performance becomes more consistent following intervention, although some post-intervention variability might be expected as participants develop their ability to use the self-talk strategy. Recently, Miller \& McAuley (1987) stated that despite the lack of continuous performance, improving a mental skill is important if it can succeed in making performance more consistent. It is interesting that participants 1,2 , and 3 not only improved performance, but post intervention data was relatively stable. In contrast participant 4's data maintained high variability throughout the study.

Although the size of the treatment effects varied across participants, all increases in performance were viewed as important for the coach. The coach felt that low-drive shooting was the most effective shooting strategy for scoring goals in soccer. He felt that post-intervention the athletes had increased their low-drive 
shooting by up to forty percent. The coach was also willing to continue working with the other members of the team in implementing the self-talk strategy to improve their low-drive shooting. The coach's support for the utilization of self-talk to improve athletic performance supports the findings of numerous studies previously reported (e.g., Kendall et al., 1990; Patrick \& Hrycaiko, 1998; Wanlin et al., 1997).

Interviews with the participants after the study revealed that even though the participants used the self-talk strategy the majority of the time, there were instances where they did not employ the strategy. Of particular interest is participant 1 who stated using the self-talk strategy $75 \%$ of the time. She had the smallest performance enhancement, was the only participant to have overlapping data points and the only participant who did not display an immediate intervention effect. Participant 2 also observed that on the occurrences that she did not use self-talk, these were the times that she "messed up" on her shooting. These observations suggest that future research should seek to verify the participants' use of the self-talk strategy following each assessment session to determine whether performance was influenced when the selftalk was not present. The results also support Wanlin et al.'s (1997) observation that athletes must be committed to undertake all aspects of the intervention to reap the benefits.

Data from the post-intervention interviews indicated that the participants believed the self-talk strategy helped them to perform the low-drive shot. They suggested two reasons for the self-talk strategy's effectiveness. First, they felt the cues helped them gain and maintain the appropriate attentional focus for the task and secondly they felt a higher level of confidence when shooting. These results were 
similar to Landin and Hebert's (1999) study with tennis players where the participants reported increased confidence and improved awareness in their volleys.

The findings of the present study are more impressive in that external factors may have altered the results of this study to some degree. Environmental and field conditions varied considerably throughout the duration of the study. The environment for data collection ranged from five to thirty degrees Celsius, through windy conditions and intense heat, to wet and dry hard fields. Although these factors may have impacted the results obtained with soccer they are likely to always be present. The conditions at a soccer practice or match will constantly be changing, which implies athletes will have to be prepared to play through all of these elements and situations.

Some recommendations for further research in this area would be to videotape the participant's low-drive shots, especially in competitions. In the game situations it was difficult for the observers as shots came off very fast. If games had been videotaped live data analysis plus video analysis could have been included. The opportunity to examine further issues such as low-drive shots that didn't reach the net, but lead to scoring opportunities could have also been observed.

Another area that would improve the study would be to look at more competitive situations. It would be advantageous to examine the participants' behavior in competitions prior to the implementation of self-talk, during intervention and post-intervention. The participants low-drive shooting performance could then be recorded over the duration of the study from a competitive perspective. 
Finally from an ethical perspective, implementing the self-talk strategy to participant 4 (non-experimental participant) prior to the final competition. By informing this participant of the self-talk strategy she would have the opportunity to implement the strategy in the competitive environment. Thereby giving her the same opportunity to enhance her performance.

In summary, the results of the present study indicate that a well-constructed self-talk strategy can enhance low-drive shooting performance in practice sessions. Low-drive shooting performance improved in practice sessions following the implementation of the self-talk strategy. Actual game day performance revealed that the participants continued to use the self-talk strategy when executing the low-drive shot. The participants' confidence in their low-drive shooting also increased, which led them to aim more for the low-corners and gave them enhanced perceptions of their ability to score with their low-drive shot. This study extends the literature on the use of self-talk with skilled athletes, and suggests that a self-talk strategy can help to improve low-drive shooting. The study also adds to the current literature by extending the sports and skills examined in sport psychology. Finally, the social validity assessment by the participants and coach indicated the intervention was enjoyable to use, and effective for enhancing low-drive shooting performance. 


\section{$\underline{\text { References }}$}

Albinson, J. G., \& Bull, S. J. (1998). Mental game plan a training for all sports. London, ON: Spodym Publishers.

Bailey, I., \& Teller, F. L. (1970). Soccer. Philadelphia, PA: W. B. Saunders Company.

Beim, G. (1977). Principles of modern soccer. Boston: Houghton Mifflin Company.

Bell, K. F. (1983). Championship thinking: The athletes guide to winning performance in all sports. Englewood Cliffs, N. J.: Prentice Hall.

Bryan, A. J. (1987). Single-subject designs for evaluation of sport psychology interventions. The Sport Psychologist, 1, 283-292.

Bunker, L., Williams, J. M., \& Zinsser, N. (1993). Cognitive techniques for improving performance and building confidence. In J. M. Williams (Ed). Applied sport psychology: Personal growth to peak performance ( ${ }^{\text {nd }}$ ed.), (pp.225-242). Mountain View, CA: Mayfield Publishing Co.

Canadian Soccer Association Coaches Manual (n.d.), National Coaching Development Program, NCCP Level 1 Coaching Course. Ottawa, ON: Coaching Association of Canada.

Defrancesco, C., \& Burke, K. L. (1997). Performance enhancement strategies used in a professional tennis tournament. International Journal of Sport Psychology $\underline{28}(2), 185-195$.

Finn, J. A., Dr. (1985). Competitive excellence: It's a matter of mind and body. The Physician and Sportsmedicine, 13 (2), 61-75. 
Halliwell, W. (1990). Providing sport psychology consulting services in professional hockey. The Sport Psychologist, 4, 369-377.

Hardy, L., Jones, G., \& Gould, D. (1996). Understanding psychological preparation for sport: Theory and practice of elite performers. West Sussex, England: John Wiley \& Sons.

Highlen, P. S., \& Bennett, B. B. (1983). Elite divers and wrestlers: A comparison between open- and closed-skilled athletes. Journal of Sport Psychology, 5, 390-409.

Hrycaiko, D. W., \& Martin, G. L. (1996). Applied research studies with single-subject designs: Why so few? Journal of Applied Sport Psychology, 8, 183199.

Hughes, C. (1980). The football association coaching book of soccer tactics and skills. London: British Broadcasting Corporation.

Kazdin, A. E. (1982). Single-case research designs: Methods for clinical and applied settings. New York: Oxford University Press.

Kendall, G., Hrycaiko, D., Martin, G., \& Kendall, T. (1990). The effects of an imagery rehearsal, relaxation, and self-talk package on basketball game performance. Journal of Sport \& Exercise Psychology, 12, 157-166.

Kirschehenbaum, D. S., Owens, D., \& O’Connor, E. A. (1998). Smart golf: Preliminary evaluation of a simple, yet comprehensive, approach to improving and scoring the mental game. The Sport Psychologist, 12, 271-282.

Kremer, J. \& Scully , D. (1994). Psychology in Sport (pp.36-58). Bristol, PA: Taylor \& Francis Inc. 
Landin, D., \& Hebert, E. (1999). The influence of self-talk on the performance of skilled female tennis players. Journal of Applied Sport Psychology, 11 (2), 263282.

Luongo, A. M. (1996). The soccer handbook for players, coaches, and parents. Jefferson, NC: Mcfarland \& Company, Inc., Publishers.

Madigan, R., Frey, R. D., \& Matlock, T. S. (1992). Cognitive strategies of university athletes. Canadian Journal of Applied Sport Sciences, 17, 135-140.

Mahoney, M. J., \& Avener, M. (1977). Psychology of the elite athlete: An exploratory study. Cognitive Therapy and Research, 1, 135-141.

Martin, G. L. (1997). Sport psychology consulting: Practical guidelines from a behavioral analysis. Winnipeg, MB: Sport Science Press.

McPherson, S. L. (2000). Expert-Novice differences in planning strategies during collegiate singles tennis competition. Journal of Sport \& Exercise Psychology, $\underline{22}(1), 39-62$.

Miller, J. T., \& McAuley, E. (1987). Effects of a goal-setting training program on basketball free-throw self-efficacy and performance. The Sport Psychologist, 1 , 103-113.

Ming, S., \& Martin, G. L. (1996). Single-subject evaluation of a self-talk package for improving figure skating performance. The Sport Psychologist, 10, 227237.

Moran. A. P. (1996). The psychology of concentration in sport performers a cognitive analysis. East Sussex, UK: Psychology Press. 
Palmer, S. L. (1992). A comparison of mental practice techniques as applied to the developing figure skater. The Sport Psychologist, 6, 148-155.

Patrick, T., \& Hrycaiko, D. (1998). Effects of a mental training package on an endurance performance. The Sport Psychologist, 12, 283-299.

Rogerson, (1998). Enhancing competitive performance of ice hockey goaltenders using centering and self-talk. Unpublished manuscript, University of Manitoba.

Rushall, B. S. (1979). Psyching in sport. London: Pelham Books.

Rushall, B. S., Hall, M., Roux, L., Sassevill, J., \& Rushall, A.C. (1988). Effects of three types of thought content instructions on skiing performance. The Sport Psychologist, 2, 28-297.

Silva, J. M. III, \& Weinberg, R. S. (1984). Psychological foundations of sport (pp.145-156). Champaign, Il: Human Kinetics Publishing Inc.

Saunders, T. (1974). Play better soccer all in colour (pp.28-33). Glasgow \& London: Mercury Books Ltd.

Thomas, T.R., \& Fogarty, G. J. (1997). Psychological skills in training in golf: The role of individual differences in cognitive preferences. The Sport Psychologist,11, 86-106.

Van Raalte, J. L., Brewer, B. W., Lewis, B.P., Linder, D. E., Wildman, G., \& Kozimor, J. (1995). Cork! The effects of positive and negative self-talk on dart throwing performance. Journal of Sport Behavior, 18, 50-56. 
Van Raalte, J. L., Brewer, B. W., Rivera, M., \& Petitpas, A. J. (1994). The relationship between observable self-talk and competitive junior tennis players' match performance. Journal of Sport \& Exercise Psychology, 16, 400-415.

Wanlin, C. M., Hrycaiko, D. W., Martin, G. L., \& Mahon, M. (1997). The effects of a goal-setting package on the performance of speed skaters. Journal of Applied Sport Psychology, 9, 212-228.

Weinberg, R., \& Gould, D. (1995). Foundations of Sport and Exercise Psychology. Champaign, IL: Human Kinetics.

Weinberg, R., Grove, R., \& Jackson, A. (1992). Strategies for building selfefficacy in tennis players: A comparative analysis of Australian and American coaches. The Sport Psychologist, 6 (1), 3-13.

Weinberg, R., \& Jackson, A. (1990). Building self-efficacy in tennis players: A coach's perspective. Journal of Applied Sport Psychology, 2 (2), 164-174.

Weinberg, R. S., Smith, J., Jackson, A., \& Gould, D. (1984). Effect of association, dissociation and positive self-talk strategies on endurance performance. Canadian Journal of Applied Sport Science, 9 (1), 25-32.

Williams, J. M., \& Krane, V. (1993). Psychological characteristics of peak performance. In J. M. Williams (Ed). Applied sport psychology: Personal growth to peak performance $\left(2^{\text {nd }} e d.\right)$, (pp.137-147). Mountain View, CA: Mayfield Publishing Co. 
Williams, J. M., \& Leffingwell, T. R. (1996). Cognitive strategies in sport and exercise psychology. In J. L. Van Raalte, B. W. Brewer (Eds.), Exploring sport and exercise psychology ( pp.51-76). Washington, DC: American Psychological Association.

Wolf, M. M. (1978). Social validity: A case for subjective measurement or how applied behavioral analysis is finding it's heart. Journal of Applied Behavioral Analysis, $11,203-214$.

Wollman, N. (1986). Research on imagery and motor performance: Three methodological suggestions. Journal of Sport Psychology, 8, 135-138.

Ziegler, S. G. (1987). Effects of stimulus cueing on the acquisition of groundstrokes by beginning tennis players. Journal of Applied Behavioral Analysis, $\underline{20}, 405-411$. 


\section{Appendix A}

Illustration of the low-drive shot

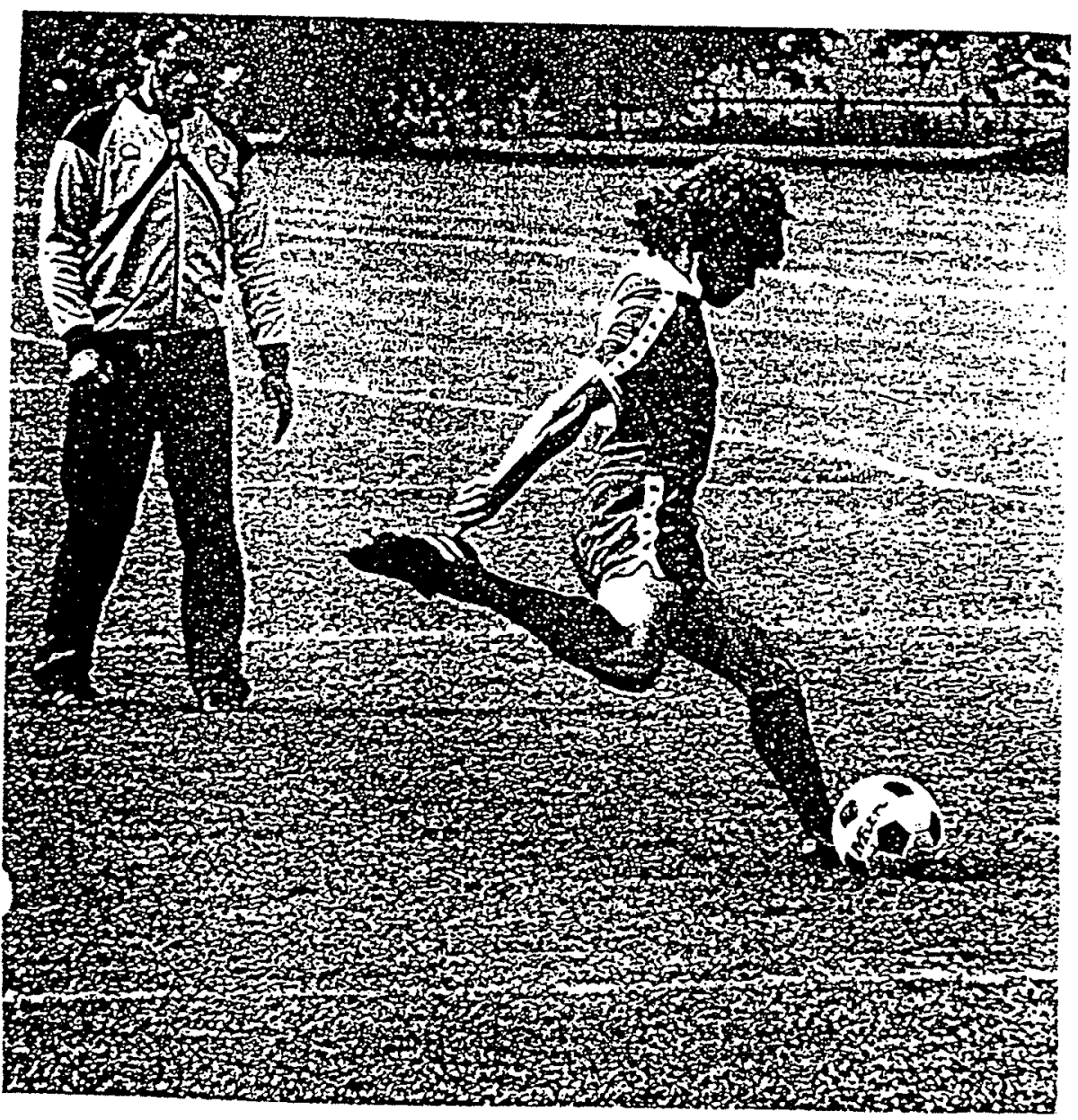

Hughes, 1980, p. 119. 


\section{Appendix B}

\section{Informed Consent for Participants}

\section{Dear Participant,}

Thank you for your interest in our study. We have selected you because we are interested in learning more about ways to improve the performance of the lowdrive soccer shot. Because you participate on the under 14 girls Provincial Soccer Team and play the position of a forward or midfielder, we would like to invite you to be involved in the study. The purpose of this study is to assess whether self-talk is an effective intervention for improving soccer shooting performance in practice and competition.

The study will run during regular scheduled soccer practices with the team and will occur over about a two-month period. Your participation involves the completion of two brief surveys, a brief interview, and engaging in a low-drive shooting drill at each of the sessions. You will be required to spend approximately half an hour or so of your own time, to complete the surveys and partake in a brief interview. The coaching staff will also be interviewed regarding your performance, and their perceptions of self-talk. Your participation in the study is voluntary, and will not affect your status with the under 14 Provincial Team. You have the right to withdraw from the study at any time and/or refrain from answering whatever questions you prefer to omit, without prejudice or consequence. All the information you provide will be number coded and strictly confidential. Findings from the study will be reported so that you cannot be identified, and be available to all participants. There will be no additional risks associated with participation. You currently execute 
the low-drive shot in both practice and game situations, and are not being asked to engage in any skill/drill that you have never done before or would pose a risk to you.

This study is a master's thesis project through the University of Manitoba. Dr. Dennis Hrycaiko is the faculty advisor, and supervisor of all research. The study has been approved by the Education/Nurses Research Ethics Board (ENREB). If you have any complaints regarding a procedure it may be reported to the Human Ethics Secretariat, or to the head of the ENREB (\#474-7122).

We are looking forward to your participation in the study. Please feel free to contact us if you have any questions or concerns prior, during, or after the study.

$\underline{\text { Janelle Johnson, B.A. (Researcher) } \quad \text { Dr. Dennis Hrycaiko, Ph. D (Advisor) }}$

Faculty of Phys. Ed. and Rec. Studies Faculty of Phys. Ed. and Rec. Studies University of Manitoba

Phone: or Phone: 474-6953

I have read and understand the permission letter. I understand that any information about my participation obtained from this research will be kept confidential. I give my consent to participate in the study.

Participant Name (Please Print)

Participant Signature

Date 


\section{Appendix C}

\section{Informed Consent for Parents/Guardians}

\section{Dear Parents/Guardians,}

Thank you for your interest in our study. We have selected your daughter because we are interested in learning more about ways to improve the performance of the low-drive soccer shot. Because she participates on the under 14 girls Provincial Soccer Team and plays the position of a forward or midfielder, we would like to invite her to be involved in the study. The purpose of this study is to assess whether self-talk is an effective intervention for improving soccer shooting performance in practice and competition.

The study will run during regular scheduled soccer practices with the team and will occur over approximately a two-month period. Your daughter's participation involves the completion of two brief surveys, a brief interview, and engaging in a low-drive shooting drill at each of the sessions. She will be required to spend approximately half an hour or so of her own time, to complete the surveys and partake in a brief interview. The coaching staff will also be interviewed regarding your daughter's performance, and their perceptions of self-talk. Her participation in the study is voluntary; and will not affect her status with the under 14 Provincial Team. She has the right to withdraw from the study at any time and/or refrain from answering whatever questions she prefer to omit, without prejudice or consequence. All the information your daughter provides will be number coded and strictly confidential. Findings from the study will be reported so that she cannot be identified, and be available to all participants. 
There will be no additional risks associated with participation. All participants currently execute the low-drive shot in both practice and game situations, and are not being asked to engage in any skill/drill that they have never done before or would pose a risk to them.

This study is a master's thesis project through the University of Manitoba. Dr. Dennis Hrycaiko is the faculty advisor, and supervisor of all research. The study has been approved by the Education/Nurses Research Ethics Board (ENREB). If you have any complaints regarding a procedure it may be reported to the Human Ethics Secretariat, or to the head of the ENREB (\#474-7122).

We are looking forward to your daughter's participation in the study. Please feel free to contact us if you have any questions or concerns prior, during, or after the study.

Janelle Johnson, B.A. (Researcher) Dr. Dennis Hrycaiko, Ph. D(Advisor)

Faculty of Phys. Ed. and Rec. Studies $\quad$ Faculty of Phys. Ed. and Rec. Studies University of Manitoba Phone: or Phone: 474-6953

I have read and understand the permission letter. I understand that any information about the participants obtained from this research will be kept confidential. I give consent for my daughter to participate in the study.

Parent/Guardian Name (Please Print)

Parent/Guardian Signature

Date

****(Circle Appropriate Relationship to the participant)*** 


\section{Appendix D}

\section{Interview Schedule-Introduction to Self-talk}

Introduce self-talk: I am here to help familiarize you with the concept of self-talk. Self-talk is the words we say or think to ourselves both inside our head and out loud. Examples of self-talk would be saying to oneself "you did a great job!", thinking through a skill for example "first I need to take a step and then swing my leg forward," or focusing your attention on something "steady, don't move,". Self-talk is pretty much any sort of conversation or dialogue that is going on inside our heads that we express by thinking or speaking.

\section{Questions regarding knowledge and usage of self-talk:}

Do you think you have ever used self-talk?

If yes, were you aware that you had used self-talk?

What types of situations would you use self-talk for?

What do you use self-talk for?

How often would you say you use self-talk?

Do you say self-talk out loud or inside your head?

\section{Teach self-talk strategy:}

The words that have been selected for the low-drive drill are "down" and "lock".

These words are cues on how the proper technique of the low-drive is implemented. To successfully accomplish the low-drive the ankle needs to be locked for a strong impact, and the foot needs to be pointed down towards the ground in order to obtain proper ball trajectory. Please say these words in a two-word sequence "downlock" every time you implement the skill in practice and competition. Please say these 
words internally (in your heads), so that the other participants are unaware of your behavior. Please do not discuss the self-talk with other participants. 


\section{Appendix E}

$\underline{\text { Recording Sheet -Practices }}$

Athlete:

Observer:

Date:

1.

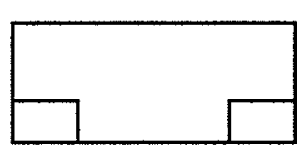

$\begin{array}{lll}0 & 1 & 2\end{array}$

4.

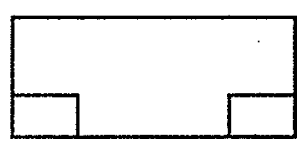

0 112

7.

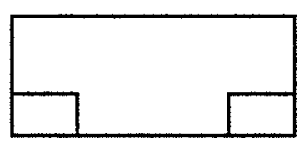

0 12

10.

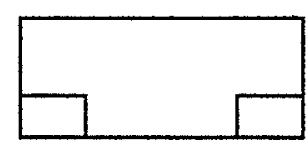

0 112

13.

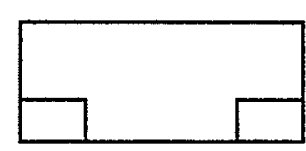

0 12
2.

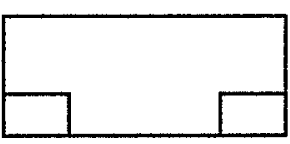

0 12

5.

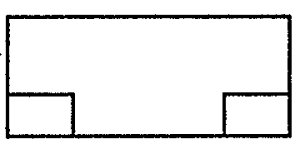

0 12

8.

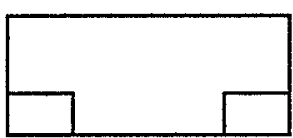

0 112

11.

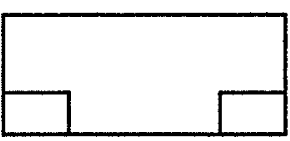

0 12

14.

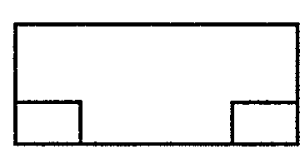

0 12
3.

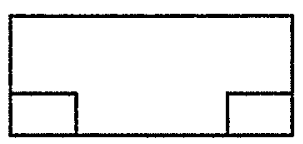

0 12

6.

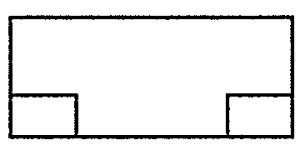

0 12

9.

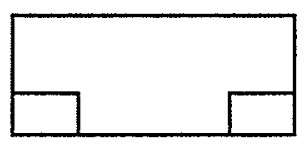

0 12

12.

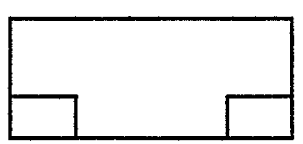

0 12

15.

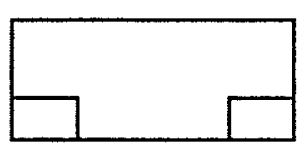

0 12 


\section{Appendix F}

Recording Sheet -Games

Athlete:

Observer:

Date:

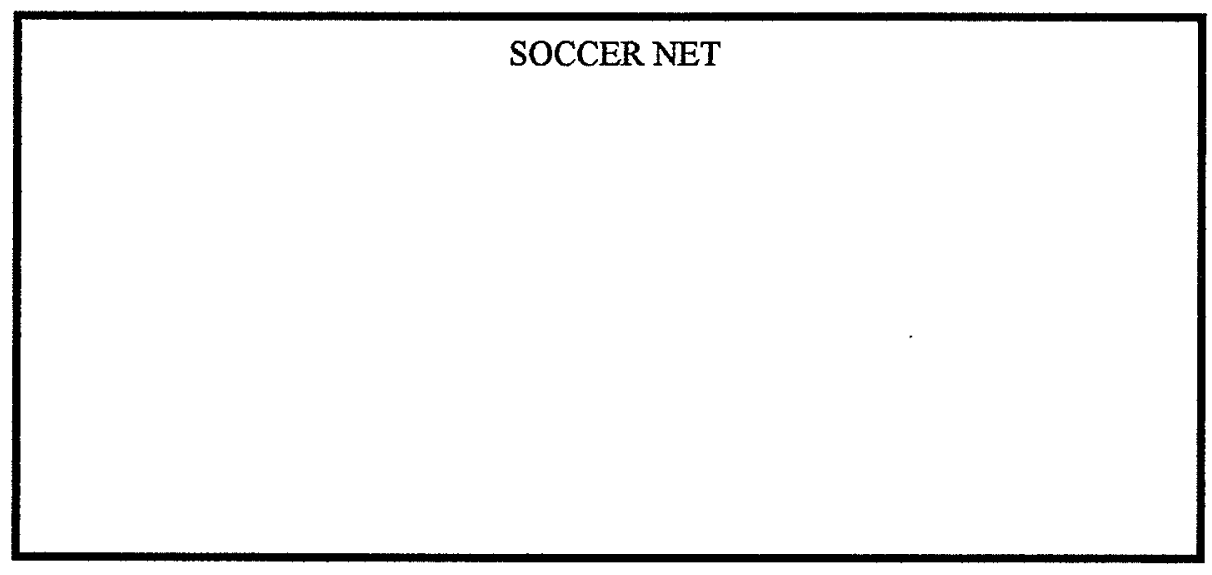

1. Number of shots taken

2. Number of low-drive shots taken

3. Number of goals scored

4. Number of low-drive goals scored 


\section{Appendix G}

\section{Low-Drive Performance Survey}

**Please Circle one answer for each question

1) How confident are you in your ability to score goals with the low-drive shot?

$\begin{array}{ccccc}1 & 2 & 3 & 4 & 5 \\ \text { not at all } & \text { very little } & \text { sometimes } & \text { confident } & \text { very } \\ \text { confident } & \text { confidence } & \text { confident } & & \text { confident }\end{array}$

2) How often do you aim for the low corners when shooting in games?

$\begin{array}{ccccc}1 & 2 & 3 & 4 & 5 \\ \begin{array}{c}\text { hardly } \\ \text { ever }\end{array} & \begin{array}{c}\text { sometimes } \\ \text { time }\end{array} & \begin{array}{c}\text { half of the } \\ \text { time }\end{array} & \begin{array}{c}\text { most of the } \\ \text { time }\end{array} & \text { all of the }\end{array}$

3) How effective are you in scoring goals with the low-drive shot?

$\begin{array}{ccccc}1 & 2 & 3 & 4 & 5 \\ \begin{array}{c}\text { very } \\ \text { ineffective }\end{array} & \begin{array}{c}\text { sometimes } \\ \text { effective }\end{array} & \begin{array}{c}\text { half of the time } \\ \text { effective }\end{array} & \begin{array}{c}4 \\ \text { effective }\end{array} & \begin{array}{c}\text { very } \\ \text { effective }\end{array}\end{array}$




\section{Appendix $\mathbf{H}$}

\section{Recording Protocol - Practice Sessions}

- Fill in the top portion of the recording sheet (athlete \#, date, your name).

- There will be one sheet per athlete, per session.

- Start at the top left hand side (\#1.), and all recordings will follow in order moving from left to right of the page.

- For each shot you will be responsible to record two items;

1. The location of the shot.

2. Rating the shot.

\section{The Location of the shot}

- The location of the shot will be marked with an " $X$ " on the net diagram ("note the mini nets appear in the drawing).

i.e.,

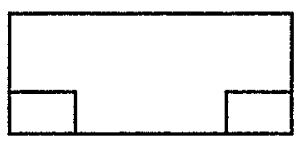

- If shots are not on net (miss the net), mark the " $\mathrm{X}$ " outside of the net location.

\section{Rating the shot}

- Directly under each picture of the net there is a series of numbers $\left(\begin{array}{ll}0 & 12\end{array}\right)$.

- The rating system :

- 0: indicates the shot was off-target (not to the bottom corners)

- 1: indicates the ball hit the miniature net within the net (i.e., post, crossbar), but did not go in the mini net

- 2: indicates shot went into the mini net

- Circle one of these three numbers for each shot.

\section{i.e., 01012}

- After each athlete is finished shooting you should have recorded the location of the shot and rated the shot for fifteen shots.

- Proceed to your next recording sheet for the following athlete.

- Hand in the recording sheets to Janelle after all five girls have finished shooting. 


\section{Appendix I}

\section{$\underline{\text { Recording Protocol - Games }}$}

- Fill in the top portion of the recording sheet (athlete \#, date, your name).

- Only shots that cross the goal/end line (on net, over, or beside) will be recorded.

- For each shot the athlete takes mark the location of where the shot crosses the goal line with an " $\mathrm{X}$ " on the net diagram.

- Include an "X" for every shot taken, even if the shots are not on net (over the net, beside the net etc.).

- If a shot is deflected into the net by the goalie etc., please mark the " $\mathrm{X}$ " as per the location the shot went, NOT where it went in the net.

- Indicate an "LD" next to the shot if it was a low-drive shot.

- If the athlete scores a goal circle the " $X$ " for that shot.

- At the end of the game fill in sections \#1 to 4 by tallying up the "X"s on the diagram of the net. 


\section{Appendix J}

Interview Schedule - Conclusions regarding self-talk

General Questions:

$\begin{array}{ccccc}1 & 2 & 3 & 4 & 5 \\ \text { not } & & \begin{array}{c}\text { somewhat } \\ \text { important }\end{array} & & \text { very } \\ \text { important } & & \text { important }\end{array}$

1. How important is it for you to improve you low-drive shooting? 12345

2. How useful did you find the self-talk strategy in this study? 12345

3. Did you enjoy using the self-talk in this study?

$\begin{array}{ccccc}1 & 2 & 3 & 4 & 5 \\ \text { not at } & & \begin{array}{l}3 \\ \text { somewhat } \\ \text { enjoyable }\end{array} & & \begin{array}{c}\text { very } \\ \text { enjoyable }\end{array}\end{array}$

\section{Interview will focus on four issues:}

Past experience and use of self-talk:

Did you knowingly engage in self-talk prior to the study?

If yes, how did you use self-talk and how often?

Did you use self-talk in any way as an attempt to enhance performance?

Verification of the use of self-talk in the study:

Did you use the self-talk strategy for the low-drive shooting?

If yes, how often would you say you used the self-talk strategy (give \%)?

Did you use the self-talk in practice and/or game situations?

Did you say the self-talk inside your head? 
Perceptions of the strategy's effectiveness:

Did the use of self-talk help/hinder your shooting in any way?

How did the self-talk help/hinder you shooting?

Insights and explanations of the function of self-talk:

Why do you think the self-talk helped/hindered your shooting?

Do you think others would have the same results as you did?

Do you think self-talk could be used in other areas to enhance performance? 


\section{Appendix K}

\section{$\underline{\text { Social Validation for Coach }}$}

$\begin{array}{ccccc}1 & 2 & 3 & 4 & 5 \\ \begin{array}{c}\text { not } \\ \text { important }\end{array} & & \begin{array}{c}\text { somewhat } \\ \text { important }\end{array} & & \begin{array}{c}\text { very } \\ \text { important }\end{array}\end{array}$

1. How important is it for your team to improve low-drive shooting? 12345

2. How important is it for your team to shoot for the low corners? 12345

3. Have you noticed any difference in the shooting performance of the following participants?

$\begin{array}{ll}\text { P1 } & \text { yes / no } \\ \text { P2 } & \text { yes / no } \\ \text { P3 } & \text { yes / no } \\ \text { P4 } & \text { yes / no }\end{array}$

4. Do you feel their low-drive shot has improved?
P1 yes / no
P2 yes / no
P3 yes / no
P4 yes / no

5. If their low-drive shot has improved, do you feel their low-drive shot has improved consistently?

$\begin{array}{ll}\text { P1 } & \text { yes / no } \\ \text { P2 } & \text { yes / no } \\ \text { P3 } & \text { yes / no } \\ \text { P4 } & \text { yes / no }\end{array}$

6. Please indicate the $\%$ the low-drive shot has improved/gotten worse?
P1 \% better/worse
P2 \% better/worse
P3 \% better/worse
P4 \% better/worse 
7. Rate these four players from 1-4, with 1 being the strongest low-drive shooter to 4 being the weakest low-drive shooter.

$\begin{array}{ll}\text { P1 } & 1234 \\ \text { P2 } & 1234 \\ \text { P3 } & 1234 \\ \text { P4 } & 1234\end{array}$

8. Who do you feel has benefited the most/ least from the intervention and why? Most: Reason:

Least: Reason:

9. (After showing low-drive performance graph) Do you consider the improvement in low-drive performance to be an important change?
P1 yes / no
$\mathrm{P} 2$ yes / no
P3 yes / no
$\mathrm{P} 4$ yes / no

10. Do you feel this intervention would benefit the rest of your team?

Yes $\quad$ No

11. Do you feel this intervention would benefit other soccer teams?

Yes No

ADDITIONAL COMMENTS: 